\title{
Atlas of Emergency Ultrasound
}

J.C. Fox, ed.

New York, NY: Cambridge University Press, 2011, 193 pages, $\$ 75$

Physicians are now able to image organs and tissues directly at the point of care, creating an immediate impact on patient well-being, and physician-performed imaging results in greater clinical self-reliance, reducing unnecessary CT scans and, thereby, radiation exposure. Surgeons looking for pathology related to the hepatobiliary system, soft tissue, and vasculature will find ultrasound information relevant to their practice.

This relatively thin book with hardcover is written by leading emergency ultrasound physicians and is designed to give the busy practicing clinician a reference tool of positive ultrasound findings. The book has 13 chapters dealing with traumatic, ocular, cardiac, pulmonary, right-upper-quadrant, intestinal, pelvic, genitourinary, musculoskeletal, pediatric, arterial, and venous ultrasound, as well as ultrasound-guided procedures. Each chapter is represented by common and notso-common pathologic entities one encounters when practicing emergency ultrasound. Over 300 detailed examples of positive ultrasound findings with 786 figures are provided, covering every organ system and illustrating the full range of pathology a clinician might encounter when using ultrasound. This book is a visually dynamic atlas, packed full of images of a broad spectrum of pathologic entities and emergency situations. Images are clear and instructive, and references are updated.

Physicians who practice primary care using ultrasonography will likely find many relevant images from which to learn, especially with regard to the gallbladder, pelvis, and vasculature, whereas physicians in the intensive care unit setting will also find the cardiac, pulmonary, and vascular chapters of particular interest. Trainees and radiologists in practice may also take a keen interest in the review of emergency sonography. A free companion Web site is available, featuring videos of specific organ systems that require a dynamic approach.

\section{E. Edmund Kim \\ M.D. Anderson Cancer Center \\ 1400 Pressler, Unit 1483 \\ Houston, TX 77030 \\ E-mail: ekim@mdanderson.org}

COPYRIGHT (c) 2012 by the Society of Nuclear Medicine and Molecular Imaging, Inc.

Published online Jul. 31, 2012.

DOI: 10.2967/jnumed.112.105437 